\title{
Erratum to: Genetic-algorithm-based multi-objective optimization of the build orientation in stereolithography
}

\author{
V. Canellidis $\cdot$ J. Giannatsis $・$ V. Dedoussis
}

Published online: 23 February 2010

(C) Springer-Verlag London Limited 2010

Erratum to: Int J Adv Manuf Technol (2009) 45:714-730

DOI 10.1007/s00170-009-2006-y

Unfortunately, an error occurred in the reference list by reference 22 .

The correct entry is given below.

22. Ang BY, Chua CK, Du Z (2000) Development of an advisory system for trapped material in rapid prototyping parts. Int J Adv Manuf Technol 16:733-738. doi:10.1007/ s001700070026

The online version of the original article can be found at http://dx.doi. org/10.1007/s00170-009-2006-y.

V. Canellidis · J. Giannatsis $\cdot$ V. Dedoussis $(\bowtie)$

Center for Product Development and Rapid Prototyping,

Department of Industrial Management \& Technology,

University of Piraeus,

80 Karaoli \& Dimitriou str.,

18534 Piraeus, Greece

e-mail: vdedo@unipi.gr 